\title{
AVALIAÇÃO DO EFEITO DA INCORPORAÇÃO DE SUBPRODUTOS AGROINDUSTRIAIS NA ELABORAÇÃO DE COOKIES
}

\section{EVALUATION OF THE EFFECT OF THE USE OF AGROINDUSTRIAL BYPRODUCTS IN THE PREPARATION OF COOKIES}

\author{
Ana Paula Travalini ${ }^{1}$, Fabiane Oliveira Farias ${ }^{1}$, Renata Mayer ${ }^{1}$, Ivo Mottin Demiate ${ }^{1}$, Ana Cláudia \\ Barana ${ }^{1}$. \\ ${ }^{1}$ Universidade Estadual de Ponta Grossa, - UEPG - Ponta Grossa - Brasil. Email: \\ acbarana@uepg.br
}

\begin{abstract}
Resumo
No processamento da cenoura e beterraba as folhas são descartadas, ainda que tenham boas propriedades nutricionais. $O$ farelo de trigo é um subproduto gerado na moagem do trigo e apresenta altos teores de fibras e proteínas. Dentro deste contexto, o objetivo deste trabalho foi desenvolver biscoitos do tipo cookie utilizando farelo de trigo (FT) e farinha das folhas de cenoura $(F F C)$ e de folhas de beterraba (FFB) em diferentes proporções, avaliando-se a aceitação $e$ intenção de compra dos biscoitos. Fez-se um planejamento experimental de mistura do tipo Simplex Centróide resultando em sete diferentes formulações. Os biscoitos possuíam uma formulação base variando os teores de FT, FFC e FFB. Uma análise sensorial dos biscoitos foi realizada com 60 provadores não treinados considerando-se os parâmetros sabor, textura, avaliação global $e$ intenção de compra. Os resultados foram satisfatórios para todas as formulações. Análises físicoquímicas das duas amostras com maior aceitabilidade revelou biscoitos com altos teores de fibras $\left(22,39\right.$ e $\left.11,34 \mathrm{~g}^{100} \mathrm{~g}^{-1}\right)$ e fonte de proteínas $\left(8,22\right.$ e 9,10g $\left.100 \mathrm{~g}^{-1}\right)$. Visto que os biscoitos apresentam propriedades nutricionais desejadas e índices de intenção de compra (73,33 e 50,00\%) a possibilidade do desenvolvimento de biscoitos do tipo cookie utilizando os subprodutos agroindustriais foi confirmada.
\end{abstract}

Palavras-chave: folha de cenoura; folha de beterraba; farelo de trigo.

\section{Introdução}

Nos últimos anos, devido à ampliação das áreas agrícolas bem como dos avanços da biotecnologia, houve importante aumento das práticas agroindustriais aumentando o número de produtos do setor (CONAB, 2012; CARRER et al., 2010). Dados do IBGE (2011) mostram que o crescimento da agricultura brasileira chegou a 4,7\% em 2010 e, como consequência, na mesma proporção cresceu a produção de subprodutos agroindustriais, com estimativas de cerca de 250 milhões de toneladas ao ano. Além da crescente produção agrícola, produtos que antes eram comercializados in natura estão sendo transformados, intensificando a geração de resíduos (PELIZER et al., 2007). 
Os subprodutos gerados dos processos industriais não possuem valor econômico evidente. No entanto, muitos desses materiais carregam consigo grandes quantidades de nutrientes, podendo se tornar insumos no desenvolvimento de outros produtos (SILVA, 2008). Grande parte desses resíduos orgânicos produzidos é encaminhada às usinas de compostagem, processo esse que produz adubo orgânico que é essencial para o solo na melhoria de sua estrutura, fertilidade e produtividade (FONTOURA et al., 2009). Porém ainda existe a necessidade de implementação de técnicas sustentáveis, capazes de converter esses resíduos em insumos de maior valor agregado e reduzir os impactos ambientais (FARINAS et al., 2008). As alternativas de valorização e aproveitamento de subprodutos da agroindústria estão recebendo incentivo, visto que podem diminuir significativamente a poluição ambiental, além de reduzir os desperdícios de matérias primas e custos de produção (FERNANDES et al., 2008).

O farelo de trigo é o principal subproduto da moenda do trigo, possui propriedades nutritivas interessantes, sendo, no entanto, destinado quase totalmente para a produção de ração animal (YUAN et al., 2008). De acordo com Piekarski (2009), na composição do farelo são encontrados 45 $\%$ de fibras, $14 \%$ de proteínas e, aproximadamente, $6 \%$ de resíduos minerais. Devido ao elevado teor de fibras em sua composição, propriedades nutricionais, características funcionais como melhora das funções intestinais e redução dos índices de colesterol e melhora dos aspectos reológicos da massa, pesquisas propõem a utilização do farelo na fabricação de pães e outros produtos derivados do trigo (KAMRAN et al., 2008).

A cenoura (Daucus carota L.), raiz tuberosa pertencente à família Umbelliferae, é uma hortaliça de grande importância econômica para o Brasil. É consumida in natura ou industrializada e excelente fonte de minerais e vitaminas para nossa alimentação (MARINGONI et al., 2012). Alguns dados mostram que em 2012 a produção de cenoura no Brasil foi de aproximadamente 780 mil toneladas (EMBRAPA, 2013). No entanto devido à falta de conhecimento sobre o potencial e de tecnologias adequadas muitas partes das hortaliças que apresentam composição e propriedades importantes são descartadas, como raízes, sementes e folhas (LEITE et al., 2011). As folhas de cenoura se enquadram bem neste contexto de aproveitamento de subprodutos por boas características nutricionais, que acabam sendo perdidas no momento da colheita com o descarte das mesmas. No trabalho de Leite et al. (2011) as folhas de cenoura apresentaram elevados conteúdos de minerais e proteínas, além de consideráveis concentrações de ácidos graxos essenciais.

A beterraba (Beta vulgaris L.), importante hortaliça cultivada no Brasil, teve sua produção aumentada nos últimos anos principalmente em função da comercialização de seus produtos minimamente processados. Dentre seus vários componentes de interesse nutricional pode-se destacar a presença de vitaminas A, B1, B2, B5 e C além de minerais como cálcio, ferro, potássio, sódio e zinco (MARCOLINI et al., 2010). Dentre as regiões produtoras de beterraba do Brasil, 
destacam-se os Estados de São Paulo, Minas Gerais e Rio Grande do Sul, que juntos somam 42 \% da produção nacional desta hortaliça tuberosa. No Nordeste a produção é limitada devido às elevadas temperaturas que acabam por alterar as características sensoriais diminuindo a qualidade da beterraba produzida (GRANJEIRO et al., 2007). Assim como as folhas de cenoura, as folhas de beterraba também são descartadas e podem apresentar propriedades benéficas. Alguns autores destacam a beterraba como uma das principais hortaliças ricas em ferro tanto em suas folhas quanto nas raízes (GRANJEIRO et al., 2007; CARVALHO e GUZZO, 2008)

Os biscoitos tipo cookies são amplamente distribuídos e consumidos devido à quantidade elevada de sabores disponíveis, custo acessível para diversas classes e vida de prateleira prolongada. Entretanto, a busca por alimentos mais saudáveis e com algum apelo funcional vem fazendo com que a indústria alimentícia se adapte a estas mudanças e os biscoitos têm sido os principais alvos destas alterações de modo que suas composições se tornem mais nutritivas e atrativas (VITALI et al., 2009).

Levando em consideração todas as informações mencionadas, este trabalho teve como objetivo a elaboração de biscoitos tipo cookies utilizando farelo de trigo e farinha das folhas de cenoura e beterraba em diferentes proporções avaliando a aceitação e intenção de compra por meio de análise sensorial.

\section{Materiais e Métodos}

\section{Material}

Para a elaboração dos biscoitos tipo cookies, desenvolvidos nos laboratórios da Universidade Estadual de Ponta Grossa, foram utilizados farelo de trigo (FT) e farinhas das folhas de cenoura (FFC) e beterraba (FFB). O farelo e a farinha de trigo foram doados pelo moinho Cidade Bella, e as folhas de cenoura e beterraba pelo Colégio Agrícola Augusto Ribas da Universidade Estadual de Ponta Grossa, ambos da cidade de Ponta Grossa, estado do Paraná.

As FFC e FFB foram obtidas a partir da lavagem e sanitização das folhas com solução de hipoclorito de sódio de 200 ppm, seguida de secagem em estufa com circulação forçada de ar a 60 ${ }^{\circ} \mathrm{C}$ durante 12 horas. Após a secagem, as folhas foram trituradas em liquidificador. Os demais ingredientes utilizados na produção do biscoito foram: gordura vegetal hidrogenada, açúcar mascavo, açúcar refinado, fermento químico em pó e essência de baunilha, sendo estes obtidos no comércio local de Ponta Grossa. A formulação base do biscoito está apresentada na Tabela 1. 
Tabela 1 - Formulação base para biscoitos tipo cookies

\begin{tabular}{|c|c|}
\hline Ingredientes & Quantidade utilizada $($ g 100g-1 $)$ \\
\hline Farinha de trigo & 45,5 \\
\hline Gordura Vegetal & 22,6 \\
\hline Água & 13,7 \\
\hline Açúcar Mascavo & 10,0 \\
\hline Açúcar Refinado & 5,0 \\
\hline Essência de Baunilha & 2,0 \\
\hline Fermento Químico & 1,2 \\
\hline FT e/ou FFC e/ou FFB & 6,0 \\
\hline
\end{tabular}

Métodos

Com o intuito de se obter a melhor formulação, utilizou-se um planejamento experimental do tipo Simplex Centróide para misturas, totalizando sete (Tabela 2). A adição dos componentes ocorreu num teor máximo de $6 \%$ sobre a formulação base, sendo que os limites para cada ingrediente foram estabelecidos a partir de ensaios prévios (33-100 \% para FT; 0-67 \% para FFC; 0$67 \%$ para FFB).

Tabela 2 - Planejamento experimental do tipo Simplex Centróide para adição de três componentes ao biscoito.

\begin{tabular}{|c|c|c|c|c|c|c|}
\hline \multirow{3}{*}{ Formulação } & \multicolumn{6}{|c|}{ Proporção dos ingredientes na mistura ternária } \\
\hline & \multicolumn{3}{|c|}{ Em pseudocomponentes } & \multicolumn{3}{|c|}{ Em concentrações reais } \\
\hline & FT (X1) & FFC (X2) & FFB (X3) & FT (C1) & FFC (C2) & FFB (C3) \\
\hline F1 & 1 & 0 & 0 & 1 & 0 & 0 \\
\hline $\mathbf{F 2}$ & 0 & 1 & 0 & 0,33 & 0,67 & 0 \\
\hline F3 & 0 & 0 & 1 & 0,33 & 0 & 0,67 \\
\hline F4 & 0,5 & 0,5 & 0 & 0,67 & 0,33 & 0 \\
\hline F5 & 0,5 & 0 & 0,5 & 0,67 & 0 & 0,33 \\
\hline F6 & 0 & 0,5 & 0,5 & 0,33 & 0,33 & 0,34 \\
\hline F7 & 0,34 & 0,33 & 0,33 & 0,5 & 0,25 & 0,25 \\
\hline
\end{tabular}

Os biscoitos foram analisados sensorialmente por 60 provadores não treinados. Cada provador recebeu sete amostras codificadas com números de três algarismos, as quais deveriam ser avaliadas individualmente quanto aos parâmetros sabor, textura e avaliação global por intermédio de uma escala hedônica estruturada de 9 pontos (9=gostei muitíssimo, 8=gostei muito, 7=gostei moderadamente, $6=$ gostei ligeiramente, $5=$ =indiferente, $4=$ desgostei ligeiramente, $3=$ desgostei moderadamente, $2=$ desgostei muito e $1=$ desgostei muitíssimo). Avaliou-se também intenção de compra dos provadores utilizando uma escala estruturada de 5 pontos $(5=$ certamente compraria, 3=talvez compraria, $1=$ certamente não compraria).

A análise sensorial foi realizada após a aprovação de parecer pelo Comitê de Ética em Pesquisa envolvendo Seres Humanos (Parecer $n^{\circ}$ 25712313.4.0000.0105) em laboratório climatizado equipado com cabines de prova individuais.

As duas formulações com maior aceitabilidade foram caracterizadas segundo as metodologias descritas pela AOAC (2000): o teor de umidade foi determinado em estufa a $105{ }^{\circ} \mathrm{C}$, 
cinzas em mufla a $550{ }^{\circ} \mathrm{C} / 5 \mathrm{~h}$, proteínas pelo método de nitrogênio total Kjeldahl e a fibra alimentar por método enzimático. A análise de lipídios foi realizada por extração sólido-líquido com Soxhlet seguindo a metodologia descrita em Instituto Adolfo Lutz (2008), enquanto o teor de carboidratos foi calculado por diferença. Todas as determinações foram realizadas em triplicata.

O planejamento experimental, assim como a análise de dados da composição físico-química e as superfícies de resposta foram obtidos utilizando o software Statistica $10.0^{\circledR}$ para Windows.

\section{Resultados e Discussão}

Como resultado da avaliação global da análise sensorial todos os cookies ficaram na região positiva da escala (>5), o que evidencia que a aceitação dos cookies pelos consumidores foi satisfatória. As médias de aceitação dos cookies com relação à textura foram altas, variando entre 6,0 (gostei ligeiramente) e 8,0 (gostei muito); o mesmo pode ser observado em relação ao sabor, exceto para as formulações 3 e 6 que variaram entre 5,0 (indiferente) e 6,0 (gostei ligeiramente) (Figura 1). Os cookies com melhores índices foram os produzidos com a formulação 1 (F1), com valores médios de avaliação global, textura e sabor de: 7,14; 7,24; 7,08, respectivamente; e com a formulação 4 (F4), com valores médios de avaliação global, textura e sabor de: 6,63; 7,07; 7,08, respectivamente. A intenção de compra destas formulações preferidas pelos provadores está exposta na Tabela 3, em forma de média, seguindo a escala hedônica de 5 pontos, assim como a porcentagem dos provadores que comprariam o produto.

Tabela 3 - Intenção de compra para os Cookies

\begin{tabular}{|c|c|c|c|c|}
\hline \multirow{2}{*}{ Amostras } & Aceitação* & $\%$ que compraria & \% com dúvida & \% que não compraria \\
\hline & & Nota $>3$ & Nota $=3$ & Nota $<3$ \\
\hline F1** & 4,10 & 73,33 & 11,67 & 15 \\
\hline $\mathbf{F} 4 * * *$ & 3,48 & 50 & 31,66 & 18,34 \\
\hline
\end{tabular}

A representação do ajuste linear para os parâmetros de textura, sabor e avaliação global, em termos de pseudo-componentes, é dada através da Figura 1, onde se observa que para os parâmetros avaliados, quanto maior o teor de FT no produto, maior a sua aceitabilidade. Formulações com até 0,5 de FFC também apresentaram resultados satisfatórios. A adição de FFB não apresentou efeito positivo para os parâmetros avaliados, sendo que para adição desta em produtos similares são necessários estudos aprofundados sobre a mesma. 

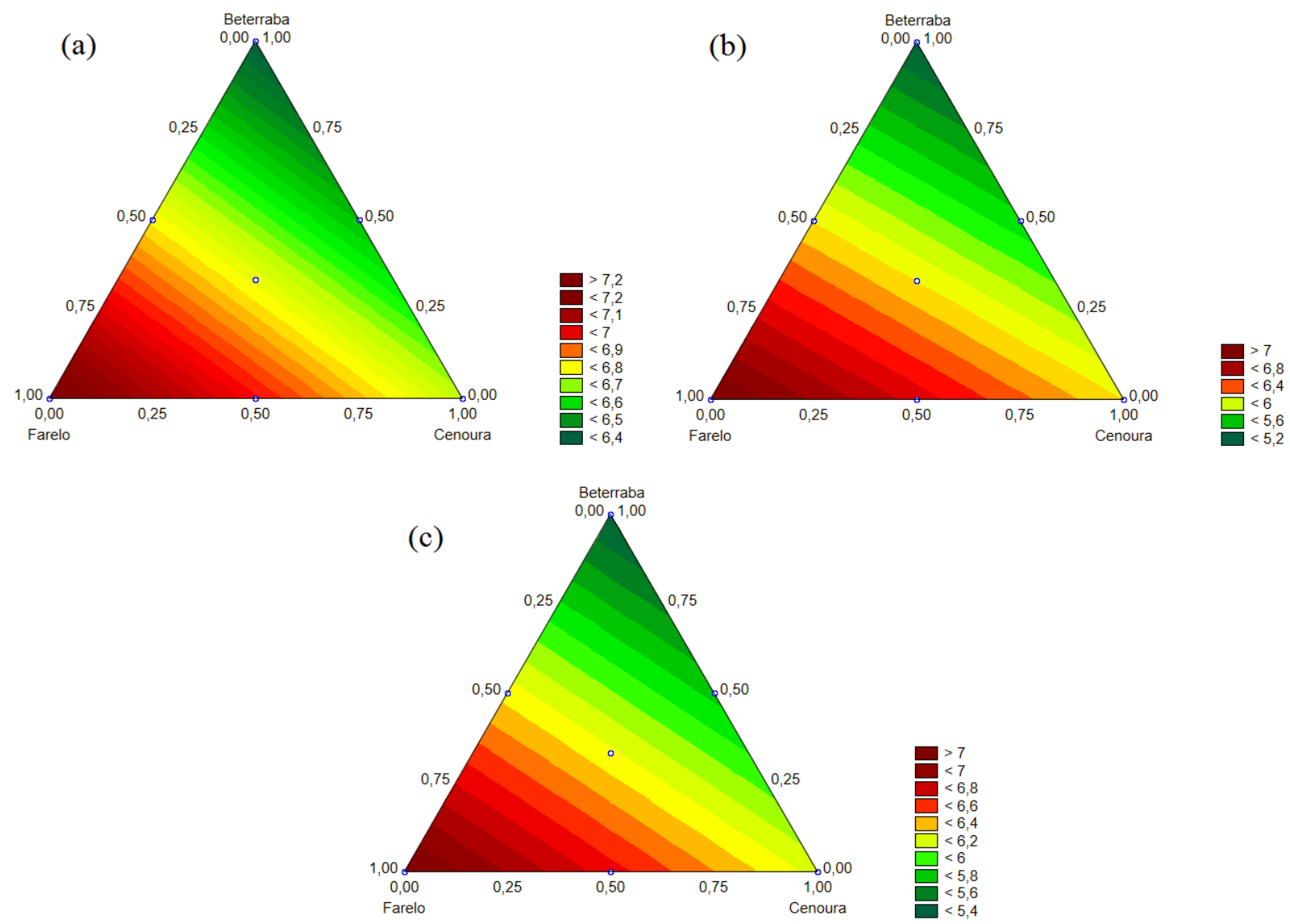

Figura 1: Superfície de resposta, de acordo com a adição das diferentes farinhas presentes no planejamento experimental para os seguintes parâmetros de Cookies: Textura (a), Sabor (b) e Avaliação Global (c).

Os coeficientes apresentados na Tabela 4 evidenciam a influência do FT nas características sensoriais do produto.

Tabela 4 - Coeficientes de regressão e análise de variância dos modelos ajustados à textura, sabor e avaliação global contendo misturas de FT, FFC e FFB.

\begin{tabular}{cccc}
\hline & Textura & Sabor & Avaliação Global \\
\hline $\boldsymbol{\beta}_{\mathbf{1}}$ & 7,20 & 7,02 & 7,13 \\
$\boldsymbol{\beta}_{\mathbf{2}}$ & 6,71 & 6,10 & 6,16 \\
$\boldsymbol{\beta}_{\mathbf{3}}$ & 6,38 & 5,17 & 5,37 \\
$\mathbf{R}^{\mathbf{2}}$ ajustado & 0,81 & 0,99 & 0,96 \\
$\mathbf{p}-\mathbf{v a l o r}$ & $<0,0001$ & $<0,0001$ & $<0,0001$ \\
${ }^{1} \mathrm{Y}=\beta_{1} \mathrm{X}_{1}+\beta_{2} \mathrm{X}_{2}+\beta_{3} \mathrm{X}_{3}$, onde $\mathrm{X}_{1}=\mathrm{FT}, \mathrm{X}_{2}=$ FFC e $\mathrm{X}_{3}=$ FFB
\end{tabular}

Os valores dos coeficientes de determinação $\left(\mathrm{R}^{2}\right)$ podem explicar de 81 a 99 \% da variância total das respostas, confirmando a adequabilidade dos modelos. Segundo Granato et al. (2013) $\mathrm{R}^{2}>$ $90 \%(0,90)$ é apenas um dos critérios para avaliar a qualidade do ajuste do modelo, um modelo matemático com $\mathrm{R}^{2}<70 \%(0,70)$ não é considerado bom, porém para avaliação de dados de análise sensorial um $\mathrm{R}^{2}>60 \%(0,60)$ é considerado satisfatório. Os valores de $\mathrm{R}^{2}$ encontrados para o trabalho em questão quanto aos parâmetros avaliados foram todos superiores a $80 \%(>0,80)$, sendo então o modelo aplicado satisfatório ao estudo podendo ser utilizado para fins preditivos quanto ao 
comportamento das respostas dentro do intervalo de variação estudado.

Os resultados das análises físico-químicas estão apresentados na Tabela 5, onde podem ser observadas diferenças significativas entre as amostras, considerando $\mathrm{p}<0,05$. Utilizou-se a análise de variância Anova de fator único, indicada para casos de comparações relativamente simples como as de análises físico-químicas (GRANATO et al., 2010). As comparações múltiplas foram realizadas utilizando o teste de diferença mínima significativa (Fisher LSD) com $\mathrm{p}<0,05$.

Tabela 5 - Composição química dos cookies $\left(\% \mathrm{~m} \mathrm{~m}^{-1}\right.$, base seca)

\begin{tabular}{ccccccc}
\hline Amostras & Umidade & Cinzas & Lipídios & Proteína & Fibra Alimentar & Carboidratos* $^{*}$ \\
\hline Formulação 1 & $1,96^{\mathrm{a}}$ & $0,77^{\mathrm{b}}$ & $25,68^{\mathrm{b}}$ & $8,22^{\mathrm{b}}$ & $22,39^{\mathrm{a}}$ & $40,98^{\mathrm{b}}$ \\
Formulação 4 & $2,77^{\mathrm{a}}$ & $1,32^{\mathrm{a}}$ & $26,87^{\mathrm{a}}$ & $9,10^{\mathrm{a}}$ & $11,34^{\mathrm{b}}$ & $48,60^{\mathrm{a}}$ \\
\hline p (Brown-Forsythe)** & 0,05 & 0,11 & 0,11 & 0,50 & 0,50 & 0,84 \\
p (ANOVA)*** & 0,119482 & $>0,001$ & 0,005 & 0,038 & $>0,001$ & $>0,001$ \\
\hline
\end{tabular}

*Carboidratos calculados por diferença. * Valor de probabilidade obtido segundo teste Brown-Forsythe para homogeneidade de variância. ** Valor de probabilidade obtido segundo Anova de fator único. *** Letras diferentes na mesma coluna representam diferenças significativas de acordo com teste de Fisher LSD ( $p<0,05)$.

Por definição, biscoitos tipo cookies são os produtos obtidos pelo amassamento e cozimento conveniente de massa preparada com farinhas, amidos, féculas e outras substâncias alimentícias, acrescido ou não de recheio ou confeitos (ANVISA, 1978). Normalmente, cookies de marcas comerciais possuem em sua formulação gotas de chocolate, porém como o intuito da elaboração dos cookies é criar um apelo funcional em relação ao elevado teor de fibras, optou-se por utilizar ingredientes mais simples na formulação.

A informação nutricional dos cookies está descrita na Tabela 6. O valor calórico foi calculado considerando $4 \mathrm{kcal} / \mathrm{g}$ para proteínas e carboidratos e, $9 \mathrm{kcal} / \mathrm{g}$ para lipídios (ANVISA, 2003). Para determinar a porcentagem do valor diário suprido pelo biscoito, considerou uma dieta com 300 gramas de carboidratos, 50 gramas de proteínas, 70 gramas de lipídios e 25 gramas de fibra alimentar, de acordo com as recomendações de ingestão diária estabelecidas pela ANVISA.

Tabela 6 - Tabela nutricional dos cookies

\begin{tabular}{|c|c|c|c|c|}
\hline \multicolumn{5}{|c|}{$\begin{array}{l}\text { INFORMAÇÃO NUTRICIONAL } \\
\text { Porção de } 30 \text { g (6 cookies })\end{array}$} \\
\hline & \multicolumn{2}{|c|}{$\mathrm{F} 1$} & \multicolumn{2}{|c|}{ F4 } \\
\hline & $\begin{array}{l}\text { Quantidade por } \\
\text { porção }\end{array}$ & $\% \mathrm{VD}^{*}$ & $\begin{array}{l}\text { Quantidade por } \\
\text { porção }\end{array}$ & $\% \mathrm{VD}^{*}$ \\
\hline Valor calórico & $128 \mathrm{kcal}=536 \mathrm{~kJ}$ & 6 & $142 \mathrm{kcal}=594 \mathrm{~kJ}$ & 7 \\
\hline Carboidratos & $12,3 \mathrm{~g}$ & 4 & $14,7 \mathrm{~g}$ & 5 \\
\hline Proteínas & $2,5 \mathrm{~g}$ & 5 & $2,7 \mathrm{~g}$ & 5 \\
\hline Gorduras totais & $7,7 \mathrm{~g}$ & 11 & $8,1 \mathrm{~g}$ & 11 \\
\hline Fibra alimentar & $6,7 \mathrm{~g}$ & 27 & $3,4 \mathrm{~g}$ & 14 \\
\hline
\end{tabular}


O teor de água de um alimento constitui-se em um dos mais importantes índices analíticos. Reflete o teor de sólidos de um produto e está diretamente ligada a sua estabilidade, sendo alimentos com elevada umidade mais perecíveis. Ambas as formulações contêm baixos teores de umidade e não apresentaram diferença significativa (Tabela 5). $\mathrm{O}$ baixo teor de umidade pode ser explicado pelo fato de tanto o FT quanto a FFC apresentaram baixas concentrações de água em suas composições. Por apresentar menor teor de umidade, os cookies podem ser caracterizados como estáveis microbiologicamente mantendo sua vida útil por mais tempo.

As cinzas, ou conteúdo mineral são os resíduos inorgânicos que permanecem após a queima da matéria orgânica. A análise de cinzas fornece informações preditivas sobre o valor nutricional de um alimento em função dos minerais. Os teores de minerais obtidos foram relativamente baixos, apresentando diferença estatística entre as duas formulações. A F4 apresentou o teor de minerais maior, este fato pode ser explicado pela presença da FFC que apresenta em sua composição altas concentrações de minerais.

Conhecer o teor de lipídios dos alimentos é muito importante para estabelecer condições de armazenamento, processamento e estocagem. Alimentos com elevados teores de lipídios são mais susceptíveis a reações oxidativas indesejáveis que alteram características de sabor, cor e odor dos produtos. Os cookies apresentaram teores médios de lipídios, variando de 25,68 \% para a F1 a 26,87 $\%$ para a F4 (Tabela 5).

Segundo a ANVISA, RDC N 80, de 13 de dezembro de 2004 o valor diário recomendado de proteínas para adultos é de $50 \mathrm{~g}$ por dia. Para um alimento ser considerado fonte de proteínas, a Portaria $\mathrm{N}^{\circ} 27$, de 13 de janeiro de 1998 da ANVISA estabelece que o produto deve conter $10 \%$ do valor diário recomendado em 100 g. Neste contexto, os cookies se enquadram como produtos fonte de proteínas. Os cookies integrais comerciais possuem aproximadamente $6 \mathrm{~g}$ de proteínas por $100 \mathrm{~g}$ estando abaixo dos valores encontrados para as duas formulações na Tabela 5.

De acordo com a ANVISA, Portaria $N^{\circ} 27$, de 13 de janeiro de 1998 um produto pode ser considerado "rico" ou com alto teor de fibras se apresentar em sua composição no mínimo 6 g por $100 \mathrm{~g}$ de produto. Ambas as formulações podem ser consideradas com alto teor de fibras sendo o teor de fibras da F1 (22,39 \%) aproximadamente quatro vezes maior e da F4 (11,34 \%) aproximadamente o dobro dos padrões estabelecidos pela legislação. Os valores dos teores de fibras apresentados na Tabela 5 são superiores aos encontrados para cookies integrais comerciais encontrados nos mercados locais, os quais possuem em média $4 \mathrm{~g}$ de fibras por $100 \mathrm{~g}$ de produto.

Os carboidratos foram os componentes majoritários na composição de ambas as formulações com valores de 40,98 \% para a F1 e 48,60 \% para F4, estando de acordo com as tabelas nutricionais de cookies comerciais. 


\title{
4 Conclusão
}

Com os resultados obtidos pode-se concluir que a utilização da farinha das folhas de cenoura e beterraba e o farelo de trigo na elaboração de cookies é uma alternativa para o aproveitamento destes subprodutos, visto que nenhuma das formulações apresentou-se nas escalas negativas da análise sensorial, destacando-se com resultados satisfatórios duas formulações, a F1, contendo apenas farelo de trigo, e a F4, resultante de uma mistura de farelo de trigo e farinha das folhas de cenoura. Observando-se os gráficos de superfície de resposta obtidos pela análise estatística para os parâmetros sabor, textura e avaliação global, conclui-se que as maiores concentrações de FT e FFC resultaram em avaliações mais favoráveis por parte dos consumidores, sendo necessárias pesquisas futuras para adequar melhor às concentrações de FFB nas formulações para que os resultados sejam igualmente positivos. As análises físico-químicas das amostras "preferidas" evidenciaram um elevado conteúdo de nutrientes em ambas as formulações podendo enquadrá-los como fonte de proteínas e de alto teor de fibras de acordo com legislações preconizadas pela ANVISA.

\begin{abstract}
When carrots and beets are processed, their leaves are discarded, even if they have good nutritional properties. Wheat bran is a by-product generated in the wheat dry milling, presenting high levels of fiber and protein. Within this context, the aim of this work was to develop cookies using wheat bran (FT) and flour of carrot leaves (FFC) and beet greens (FFB) in different proportions and evaluating their sensory acceptance and purchase intent. A Simplex Centroid experimental design of mixtures was carried out resulting in seven different formulations. The biscuits had a base formulation varying levels of FT, FFB and FFC. A sensory analysis was carried out with 60 untrained tasters considering the parameters flavor, texture, overall acceptability and purchase intent. The results was satisfactory for all formulations, however physicochemical analyses were performed of the two samples with higher acceptability, which revealed cookies with

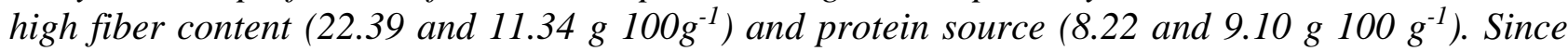
the cookies have desired properties, nutritional indices and purchase intention (73.33 and $50.00 \%)$ the possibility of developing cookies using the studied agroindustrial byproducts was confirmed.
\end{abstract}

Key-words: carrot leaf; beet greens; wheat bran.

\section{Referências}

ANVISA. Agência Nacional De Vigilância Sanitária. Resolução CNNPA Nº 12 de 1978, disponível em <www.anvisa.gov.br/anvisalegis $>$. Acesso em nov. 2013.

ANVISA. Agência Nacional De Vigilância Sanitária. Portaria $\mathbf{N}^{\circ}$ 27, de 13 de janeiro de 1998, disponível em <www.portal.anvisa.gov.br>. Acesso em nov. 2013.

ANVISA. Agência Nacional De Vigilância Sanitária. Resolução RDC no 360, de 23 de dezembro de 2003, disponível em < www.portal.anvisa.gov.br $>$. Acesso em nov. 2013.

ANVISA. Agência Nacional De Vigilância Sanitária. Resolução - RDC N 80, 13 de dezembro de 2004, disponível em < www.portal.anvisa.gov.br>. Acesso em nov. 2013.

AOAC. Association of official analitical chemistry. Official methods of analysis of the Association of Analytical Chemists International. 17 ed. Washington: AOAC, 2000. 
CARVAlHO L. B.; GUZZO C. D. Adensamento da Beterraba no Manejo de Plantas Daninhas. Revista Planta Daninha, v. 26, n. 1, p. 73-82, 2008. http://dx.doi.org/10.1590/S0100-83582008000100008

CARRER H.; BARBOSA L. A.; RAMIRO A. D. Biotecnologia na Agricultura. Estudos Avançados, v.24, n.70, p. 149-164, 2010. http://dx.doi.org/10.1590/S0103-40142010000300010

CONAB. Companhia Nacional Do Abastecimento-. Acompanhamento da Safra Brasileira - Grãos, Safra 2012/2013, disponível em < www.conab.gov.br > Acesso em out. 2013.

EMBRAPA. Empresa Brasileira de Pesquisa Agropecuária. Produção de Hortaliças no Brasil. Brasília, 2013, disponível em < http://www.cnph.embrapa.br/paginas/hortalicas_em_numeros/producao_hortalicas.pdf >. Acesso em mar 2014.

FARINAS S. C.; LMO V.; ZÚÑIGA R. F. U.; NETO B. V.; COURI S. Avaliação de Diferentes Resíduos Agroindustriais como Substratos para a Produção de Celulases por Fermentação Semi-Sólida. EMBRAPA - Empresa Brasileira de Pesquisa e Agropecuária. Boletim de Pesquisa e Desenvolvimento, São Carlos, 2008, disponível em < http://www.infoteca.cnptia.embrapa.br/handle/doc/31744>. Acesso em out. 2013.

FERNANDES A. F.; PEREIRA J.; GERMANI R.; OIANO-NETO J . Efeito da Substituição Parcial da Farinha de Trigo por Farinha de Casca de Batata (Solanum Tuberosum Lineu). Ciência e Tecnologia de Alimentos. v.28, p. 56-65, 2008. http://dx.doi.org/10.1590/S0101-20612008000500010

FONTOURA W. L.; MARQUES L. F. S.; ROOS J. L. B.; MARQUES D. F. Tratamento de resíduos sólidos por processo de compostagem. In: $2^{\circ}$ Seminário de Agroecologia de Mato Grosso do Sul. Uso e Conservação dos Recusos Naturais. Revista Brasileira de Agroecologia, v. 3, n. 2, 2009.

GRANATO D.; RIBEIRO J. C. B.; CASTRO I. A.; MASSON M. L. Sensory evaluation and physicochemical optimisation of soy-based desserts using response surface methodology. Food chemistry, v. 121, n. 3, p. 899-906, 2010. http://dx.doi.org/10.1016/j.foodchem.2010.01.014

GRANATO D.; DE ARAÚJO CALADO V. M.; JARVIS B. Observations on the use of statistical methods in food science and technology, Food Research International (2013), doi: 10.1016/j.foodres.2013.10.024

GRANJEIRO L. C.; NEGREIROS M. Z.; SOUZA B. S.; AZEVEDO P. E.; OLIVEIRA, S. L.; MEDEIROS, M. A. Acúmulo e Exportação de Nutrientes em Beterraba. Ciência e Agrotecnologia, v. 31, n. 2, p. 267-273, 2007

IAL. Métodos químicos e físicos para análise de alimentos. In. Normas Analíticas do Instituto Adolfo Lutz. 3. São Paulo: IMESP, v.1, p.42-43, 2008.

IBGE. Instituto brasileiro de geografia e estatística. Indicadores Agropecuários (2011), disponível em < www.ibge.gov.br/estatística >. Acesso em out. 2013.

KAMRAN M.; SALEEM N.; UMER Z. N. Ready-to-Eat (RTE) Wheat Bran Breakfast Cereal as a High-Fiber Diet. Journal of Food Processing and Preservation. v. 32, p.853-867, 2008. http://dx.doi.org/10.1111/j.17454549.2008.00218.x

LEITE W. C.; BOROSKI M.; BOEING S. J.; AGUIAR C. A., FRANÇA B. P.; SOUZA E. N.; VISENTAINER V. J. Chemical Characterization of Leaves of Organically Grown Carrot (Dacus carota L.) in Various Stages of Development for Use as Food. Ciência e Tecnologia de Alimentos. v.31, n.3, p.735-738, 2011. http://dx.doi.org/10.1590/S010120612011000300028

MARCOLINI L. W.; CARVAlHO L. B.; CRUZ M. B.; ALVES P. L. C. A.; CECÍlIO-FILHO A. B. Interferência de Caruru-de-Mancha sobre características de Crescimento e Produção da Beterraba. Planta Daninha. v.28, n.1, p.41-46, 2010. http://dx.doi.org/10.1590/S0100-83582010000100005

MARINGONI C. A.; BALDINI G. F. L.; DEMANT R. A. L.; EVANGELISTA M. R.; FUJITA, E. Ação de Fungicidas no Controle da Queima das Folhas e nas Características Físico-Químicas da Cenoura CV. Nantes. Revista Brasileira de Produtos Agroindustriais. v.14, n.2, p. 161-165, 2012.

PELIZER H. L; PONTIERI H. M; MORAES O. I. Utilização de Resíduos Agroindustriais em Processos Biotecnológicos como Perspectiva de Redução do Impacto Ambiental. Journal of Technology Management \& Innovation. v. 2, n. 1, p.118-127, 2007. 
PIEKARSKI, W. B. V. F. Folha de Abóbora: Caracterização Fisico-Química, Mineral e Efeito da Adição na Reologia da Massa e na Qualidade Sensorial de Pães Contendo Fibra Alimentar. Curitiba, 2009.165 f. Dissertação (Mestrado em Tecnologia de Alimentos) - Universidade Federal do Paraná.

SILVA, P. E. Validação de Método de Extração e Análise Multiresíduo de Agrotóxicos em Carne Bovina por Cromatografia Gasosa. Viçosa, 2008. 119 f. Dissertação (Mestrado em Agroquímica) - Departamento de Química Universidade Federal de Viçosa.

VITALI D.; DRAGOJEVIC I. D.; ŠEBECIC B. Effects of Incorporation of Integral Raw Materials and Dietary Fibre on the Selected Nutritional and Functional Properties of Biscuits. Food Chemistry. v.114, p.1462-1469, 2009.http://dx.doi.org/10.1016/j.foodchem.2008.11.032

YUAN X.; WANG J.; YAO H. Antioxidant Activity of Feruloylated Oligosaccharides From Wheat Bran. Revista Brasileira de Zootecnia. v.37, n.1, p.67-72, 2008.

Submetido em 27 mar. 2014, Aceito para publicação em 23 jun. 2014, Publicado em 28 dez. 2014. 